\title{
Re-Conceptualising Coach Education from the Perspectives of Pragmatism and Constructivism
}

\author{
Tatiana Bachkirova \\ Oxford, UK
}

\author{
Peter Jackson \\ Oxford, UK
}

\author{
Judie Gannon \\ Oxford, UK
}
Ioanna Iordanou
Oxford, UK

\author{
Adrian Myers \\ Oxford, UK
}

\begin{abstract}
The aim of this paper is to offer a coherent philosophical position to underpin the task of the education of coaches. Our argument builds from an analysis of the specificity and issues concerning the development of coaches. We provide a potential explanation of these issues by identifying a significant discrepancy between two typical conceptualisations of coaching that in turn leads to differences in the principles of training, education and validation of coaching expertise. In contrast to a dominant modernist view, we argue for a conceptualisation that is based on the perspectives of pragmatism and constructivism that, in our view, better aligns with the fundamental attributes of professionalism as well as the way coaches see themselves. We describe how elements reflecting this position are operationalized in the educational programmes that we offer, together with a discussion of the consequences of applying these principles and implications for coaching stakeholders.
\end{abstract}

Keywords: coaching, education and development of coaches, pragmatism, constructivism, developmentalism 


\section{Background and the issues of developing coaching practitioners}

To appreciate the challenges of coach education it is important to acknowledge that coaching is different in important ways from other practices, disciplines, and professions. Becoming a coach seems to be an endeavour typically undertaken later in life, when one has already been trained/educated in a different field. Although some similar disciplines, such as youth and widening participation mentoring or sports coaching might attract younger learners, for the majority of professional and life coaches, coaching is a second career. A comprehensive survey (428 participants) by Bono et al (2009) shows the average age of coaches as 48.43 with years coaching 9.5 . Over the last few decades, the rapid growth in the practice of coaching has seen a multitude of coaches entering the field from a variety of backgrounds, including business, human resource management, education, psychology, counselling and psychotherapy (Bluckert, 2004; Bachkirova et al., 2014). The demographic of largely mature learners brings with it pluses and minuses; on the one hand there may be focus, determination, commitment to lifelong learning, and desire for a 'second' bite of the education and development 'cherry'; on the other, practitioners may bring more entrenched views and practices of the way humans interact and function in the world.

The current literature on coaching education suggests that the growth of coaching has been in part facilitated by a simultaneous expansion in coach education offered by higher education institutions, training companies and professional bodies (Lane, 2017; Gray, et al, 2016; Gray, 2011). In the UK and North America, the upturn of provision of coach educational programmes, predominantly at postgraduate level, have been identified by a variety of sources (Fillery-Travis \& Collins, 2017; Gray, et al, 2016; Stein et al, 2014; Western, 2012; Drake, 2008). Both the number of postgraduate courses in coaching in the UK and the number of institutions offering continuing education in coaching in the USA have reached triple figures (Fillery-Travis \& Collins, 2017). Private providers also offer training and education in this market, many of which are affiliated to associations and/or educational institutions. A brief overview such as this, however, obscures significant differences in the premises underpinning learning and development, and a systematic evaluation of the coaching educational provision is somewhat overdue.

In this introduction, we discuss a number of issues associated with the education of coaches. Some of them are useful to consider in comparison to 
other complex professions, others could be seen as unique to coaching because of the way it is conceptualised.

\section{Differences in the 'rites of passage'}

To start our analysis, we note that the 'rite of passage' to coaching practice does not follow a pattern apparent in other established 'liberal' professions, where an initial academic qualification is a clear pre-requisite to becoming, say, a doctor, lawyer or engineer. It is interesting therefore, to compare coaching with other similar fields of practice, such as consulting, counselling and mentoring. In management consulting, for example, expertise and experience feature widely with little formal professional education (Greiner \& Ennsfellner, 2010; Visscher, 2006), aside from a very few educational programmes beyond the ubiquitous MBA. Training in consultancy tends to focus on specific areas, techniques or models rather than critical evaluation of existing approaches, models and practices. The opposite is evident in counselling and psychotherapy, where tight regulation of educational courses at all levels exists and accreditation and continuing professional development (CPD) are mandatory (e.g. Bond, 2015).

A rapid growth in the demand for coaching has led to an equally rapid growth in short courses with varying credentialing opportunities (Fillery-Travis \& Collins, 2017; Lane, 2017; Stein et al., 2014). Given the attractiveness of this relatively simple access to practice, the academic route to study coaching, although available, is not necessarily pursued by all. At the same time, various professional bodies offer individual accreditation systems that may serve as a 'rite of passage.' However, accreditation is usually specific to one particular coaching body, and is modelled on short training programmes with a focus on developing skills and completing coaching hours, rather than on enhancing critical thinking and understanding expected in academic study (Bachkirova \& Lawton Smith, 2015).

Bachkirova \& Lawton Smith (2015) argued that there are various issues that follow from the situation as described above. Firstly, there is a polarisation between qualification and accreditation of coaches that creates confusion for stakeholders and particularly newcomers, faced with a plethora of terms such as accreditation, certification, licensing, validation, etc. Secondly, the close interrelationship between training providers and professional bodies along with the absence of an independent party that can question the evidence base and quality of training and accreditation may undermine the credibility of both. At the same time, the formal neutral qualification route provided by universities becomes 
separated from this coupled relationship. Thus, we see that universities and professional bodies drift apart, resulting in an even wider gap between the training and the education of coaches. Training becomes learning how to coach and an entry to the profession, whereas education is something extra that leads to research and development of knowledge and therefore might not be necessary for those strongly oriented to being just practitioners. In our view, this leads to an impoverished image of coaching as a mechanical process and of the coach just as a technician.

This is not to say that a very concrete coaching approach to helping people to explore next steps is not useful. In principle, it is well justified as an activity that anyone can provide. However, coaching as a professional practice offers much more than that and therefore requires a level of study that matches its complexity. By using the term 'professional practice' and 'professionalism' we are not subscribing necessarily to the ambition of coaching to become a profession in the sense of an exclusive community (see the reasons for this in Lane, et al., 2014). Rather, we see professionalism as an important aspiration to high levels of service encompassing expertise and situational judgment; commitment to quality and ethical standards; integrity and accountability; and, therefore, consistency and rigour in the education and development of practitioners as a prerequisite (Lane, 2017; Health and Care Professionals Council, 2014).

\section{The debate about skills and academic abilities}

In differentiating coaching as professional activity, the applicability of Wampold's assertion that in psychotherapy "the person of the therapist is the critical factor in the success of the therapy" (Wampold, 2001, p. 202) is becoming widely accepted in the coaching field (de Haan et al., 2013). In the light of this, it follows that coaching 'capability' spans much wider domains in comparison to just knowledge of practice methods.

Garvey (2017) helpfully differentiates three foci of professional knowledge: episteme, techne and phronesis. Episteme is the knowledge of the field, while techne refers to the skills employed. We generally have no issue with assuming that academic study clearly incorporates these two aspects of knowledge. Yet experienced practitioners without qualifications can frequently be heard to deride qualifications as "a bit of paper", as if such qualifications ignore the third element: phronesis, or the higher-order thinking abilities applied to a particular domain, or one might say practical wisdom. Yet quite the opposite can and should be the case. For example, the descriptors to which UK 
Higher Education Institutions match their programmes (The Quality Assurance Agency for Higher Education - QAA) clearly address both the value of conceptual understanding and the integration of that knowledge into practice. The descriptors for Masters level education include a range of different aspects of the student's learning. For example, one descriptor specifies "a critical understanding of current problems and/or insights [at] the forefront of their [...] field of study or area of professional practice" (QAA, 2017, p. 28). Another highlights "conceptual understanding that enables the student [...] to evaluate methodologies and develop critiques of them and, where appropriate, to propose new hypotheses" (p. 28). It would be unusual if there were professionals who would not want their practice to be informed by such skills. However, the realities of the current 'rite of passage', privileging short-term training programmes, results in coaches that might lack these skills.

We also note that in contrast to short skills oriented programmes, locked in one paradigm of purpose, higher education aims to equip the citizen for understanding and challenging, if necessary, the established state of organisations and societies, thus expanding the paradigm. Coaching itself can be conceived, like education, as an emancipatory process. Therefore, study of the complexity and diversity of coaching adds to debates on why the short, sharp insights into coaching provided by training programmes may lack the depth, deliberation and durability required for coaching to be a force for wider social change and human emancipation (Shoukry, 2017).

\section{Multidisciplinarity of coaching}

Further challenges of an approach to coach education rest on the way the coaching discipline itself relates to other disciplines (Western, 2012; Drake, 2017). The coaching discipline draws from several others fields of knowledge (Bachkirova, 2017; Cox et al., 2014). They include generic disciplines such as philosophy, psychology, biology, sociology and the humanities, as well as more specific disciplines such as ethics, adult development and organisation studies. Closer in nature to coaching are other applied disciplines such as psychotherapy, Human Resource Development and training, and perhaps closest still, counselling, mentoring and consulting. This diversity has been nourishing ongoing debates on the discipline's 'conceptual foundation' (Nelson \& Hogan, 2009). Indeed, while there are several theories and bodies of knowledge that contribute to the emerging 'conceptualisation' of coaching (Bachkirova, 2017; Bachkirova et al., 2014), it is important to understand that the knowledge-base of coaching is creative and pluralistic (Bachkirova, 2017, p. 35). Together with acknowledging and appreciating this disciplinary 
richness, we need to admit that this inevitably creates significant diversity in terms of the learning expectations of coaching and a challenge for educators and trainers to develop inclusive, coherent and integrated programmes that satisfy such expectations (e.g. Lane, 2017; Gray et al., 2016; Bachkirova \& Lawton Smith, 2015).

\section{Making sense of these issues}

In making sense of these issues, we acknowledge that there is, unfortunately, a limited, if not growing, literature on educating coaches (Bachkirova \& Lawton-Smith, 2015; Gray et al., 2016; Lane, 2017; Garvey, 2017). In the main, it addresses the challenges around accreditation and incongruities of programmes accommodating critical thinking, skills development, practical experience, self-development, reflection and reflexivity (Gray et al., 2016; Lane, 2017, Garvey, 2017).

Gray et al. (2016), for example, identify in their critique that coach development programmes typically include a variety of psychological theories alongside those of adult learning and development. Other typical features of coach education programmes comprise the necessity for participants to build their own models of practice and the use of portfolios in demonstrating their experience and methods (Gray et al., 2016; Western, 2012). Commentators highlight the strengths of such elements, including the value of critically applying and enacting models suited to their personal skills, knowledge and attributes and self-development in creative ways, whilst simultaneously identifying the challenges of determining quality in assessment infrastructures which may be inflexible. Tackling such diverse knowledge bases in sufficient depth for analysis to be deemed critical and rigorous is difficult (Drake, 2017; Garvey, 2017; Gray et al., 2017; Western, 2012).

Reviewing this literature in light of the documents produced by professional bodies, a split becomes apparent between the ideas of education and training, academia and professional bodies, episteme and techne of coaching and in the conceptualisation of a developmental route for coaching practitioners. There is also a lack of conversation between the advocates of these sides and thus limited cross-fertilisation of ideas. Speculating about the reasons for this state of affairs, we believe that the different positions and critiques of each side are coming from the different agendas of the stakeholders that stem from, or are connected to, different principles and values about what coaching is in the first place, and what it is for. 
In the academic literature, diverse conceptualizations of coaching have been emerging as an amalgamation of various paradigms, including postmodernism (Garvey, 2011), post-positivism (Grant, 2013; Palmer, 2008; Boyatzis, 2006), social constructionism (Drake, 2015; Stelter, 2014), and critical theory (Western, 2012), amongst others (Bachkirova, 2017). Such conceptualisations 'define what is possible in practice, what theories and methods of practice are relevant and how the outcomes of practices can be evaluated' (Bachkirova, 2017, p. 31). The most notable tension could be identified between the tendencies of modernism and critique of these tendencies from the postmodern perspectives (Bachkirova, 2017).

If we review the literature by practitioners to this analysis, the demarcation line becomes blurry. On the one hand, there is a strong emphasis on goals, techniques and the impact of interventions (e.g. Rogers, 2012) - a typically modernist pursuit. On the other hand, the ambition for coaching is often formulated in humanistic terms, with the transformation of the client seeming to be the pinnacle of the process. It is interesting that the more humanistic aspect tends to be advocated in contrast to the old medical model (e.g. Krapu, 2016), arguing together with 'positive psychologists' that the client is 'creative, resourceful and whole' (p. 13), but trying to dress it in new scientific clothes. We, however, see the above tension as having outgrown its relevance and as now overplayed from the early stages when coaching was trying to differentiate itself from counselling and feeding the positive psychology movement. In any case, in the education and training of coaches, the medical model was not as influential to warrant significant attention.

Our argument is that the main issue in the development of coaches lies in still too powerful a modernist worldview. A coupled relationship between competency-based accreditations and training programmes leads to a reductionist view on the coach as a professional and how he/she is educated. Postmodern literature on coaching (e.g. Garvey, 2011), although providing a powerful critique of reductionism, shies away from offering practical approaches to education of coaches. Therefore, we believe that another philosophical position is required, and that one based on pragmatism and constructivism is more productive for addressing the issues of coach education. This becomes most apparent when we consider the differences in the way coaching and the purpose of coaching are conceptualised from what we call: value-neutral instrumentalism and developmentalism. 


\section{Explaining our position}

According to value-neutral instrumentalism coaching is seen as a professional service provided to clients in order for them to achieve their goals, whatever these goals might be. It requires techniques and skills of the coach. The coach is almost a value-neutral holder of useful tools professionally applied. The approach that is used is largely consistent for every client and can become increasingly efficient. In this model, competency-oriented training is an appropriate way of educating coaches.

According to developmentalism, which we see as corresponding to the main principles of Dewey's pragmatism (2016), development could be seen as both the means and the end of coaching. According to this position coaching is a meaningful dialogue in which new ideas, values and actions are conceived with an overarching aim of developing the overall capabilities of clients to engage with their environment. It may happen in ways that are not specified at the start. Because the approach depends on the quality of relationship with the client, who the coach is as a person, and the psychological state of both client and coach, it is by nature highly unpredictable. Educating coaches within this paradigm is therefore about developing the coach as an instrument of coaching (Bachkirova, 2016).

It is inevitable that the educational approaches for these different conceptualisations of coaching would differ. Although it might be argued that these two views are compatible and should be equally present under ideal conditions, the practicalities of developing training and education programmes require an emphasis on either one or another. By practicalities we mean the length of the programme, the requirements of awarding bodies and the expectations and commitment of the learners.

Making explicit that the philosophy of pragmatism and constructivism provides a broad framework for our choice, we have to acknowledge that our concerns about practicalities and principles have been shared in more mature disciplines such as education (Eisner, 2002) and health (Kim, 1999; White, et $a l ., 2006)$ but have not been widely articulated in coaching. While there is significant reference to writers on pragmatist and constructivist learning across the coaching literature (Schön, Kolb, and Knowles could almost be thought of as core theorists for coaches) this tends to focus on the practical aspects of the coaching process. However, it is becoming more noticeable that writers taking similar views to ours of professional development in coaching make broad reference both to pragmatists such as Dewey (e.g. Cox, 2013; Garvey, 2017; 
Bachkirova, 2017), and constructivists such as Vygotsky (Garvey et al, 2014), Bruner (Garvey et al., 2014) and Piaget (Jackson, 2004).

While these influences have existed as themes in the critical coaching literature generally, more recent theory has linked constructivism and pragmatism both as a way of thinking about coaching, and as a specific way forward for the discipline. Cox (2103), for example, immediately posited coaching as "a facilitated, dialogic, reflective learning process" (Cox, 2013, p. 1). Not only does this definition encapsulate both pragmatic and constructivist elements, but Cox goes on to argue that such a position democratises and personalises the learning process; her book is even sub-titled "A pragmatic inquiry into the coaching process". Bachkirova (2017, p. 31) similarly describes coaching as "a process of joint meaning-making" and "a complex interpretative process." Bachkirova (2017) also outlines the more optimistic solution that pragmatism offers to the tension between the potential superficiality of modernist attitudes, and the potential cynicism of post-modernist positions.

In the following section, we describe the explicitly formulated intentions for coach education that follow from our pragmatist and constructivist philosophy:

1. Developing the coach as an instrument of practice

2. Increasing reflexivity and criticality

3. Highlighting uncertainty, complexity and paradoxes in the contexts of practice

4. Practising and arriving at congruence between the self and style of practice

5. Developing ethical maturity

\section{Developmentalism in action}

\section{Developing the coach as an instrument of practice}

It follows from the above that the main underlying intention of our programmes is to develop the self of the coach as the route to effective practice. It is derived from the logic that is applicable for all complex professions, but particularly relevant to coaching. Alvesson (2001) has argued that in complex professions, knowledge and specific intellectual skills are intertwined with less 'technical' qualities such as flexibility, social skills, genuine interest in the client and other expressions of who the practitioner is as a person. 
Consequently, it is not possible to identify what would be the main factor in the successful professional contributions. Even when clients evaluate the quality of service, such evaluation is a subject of a personal relationship with practitioners and the image practitioners create.

Coaching has other factors that make the role of the "professional as a person" even more prominent. As the agendas of coaching often involve topics of high personal relevance for the client, the process requires that the practitioners connect with clients on a personal level, creating relationships that could be described as intimate in the widest sense of its term (de Haan et al., 2013; Western, 2012). In creating such a relationship and making decisions in the process of coaching, the coach's whole self is expressed in his/her interventions as they "are initiated not only from the knowledge and understanding of the clients' situation, context, psychological makeup and goals, but also from the personal resonating with all of these in the moment" (Bachkirova, 2016, p. 144).

The developmentalist approach is also specifically not value neutral. Coaches' own beliefs and values are behind their association with certain coaching schools and traditions. Their use of explicit theoretical models is value-charged in practice, as the coach's choices of approaches and interventions are intertwined with their personal values. Therefore, it is not possible to say which interventions come from theories and which from personal beliefs.

A clear consequence of such conceptualisation of coaching and of the coach is that the uniqueness of each coach is highly valued. In this light, moulding the coach into a "one fit for all" approach does not make sense at any stage of development or assessment of the coach (Bachkirova \& Lawton Smith, 2015; Garvey, 2011; Bachkirova, 2016). In this paper, we are mainly concerned with the nature of educational programmes and the way such uniqueness can be taken into consideration, nourished, but also stretched and encouraged to unfold further. As noted previously, learning the basic skills and the knowledge base of the discipline should be on offer as a foundation of practice. However, the underlying focus of the educational process is on the self and the next step in coach development, enabling coaches to create their own unique style of practice and to be congruent with their role of a coach. To achieve this aim, criticality and reflexivity are two sides of the developmental process. 


\section{Increasing criticality and reflexivity}

Criticality is essential because the objective of coach education is not only to assimilate the knowledge of the discipline, but to evaluate it, to be discerning about it, to be able to identify what knowledge is meaningful and in what contexts. Critical thinking is therefore amongst the most strongly advocated skills in postgraduate education (Wright, 2012; Cox, 2013; Bolton, 2014) and strongly aligned to the academic study of coaching in the developmentalist paradigm. Critical thinking entails "making sense of the world through a process of questioning the questions, challenging assumptions, recognising that bodies of knowledge can be chaotic and evolving" (JonesDevitt \& Smith, 2007, p. 7). It also creates opportunities for new meaning making that enable coaches to understand that their idiosyncratic interpretations can be diverse from those of others. Criticality has an important role to play in helping coaches develop a more "sophisticated understanding" about the essence of knowledge and how it is most appropriately generated and used, respecting the pluralism of theories and models that inform the coaching practice (Bachkirova, 2017, p. 38).

Reflexivity is equally important for coaches in order to become aware of their values and principles of change and development, of their drives and intentions as an element of building an approach to practice that is congruent with their understanding of the way they are. A wider concept of reflection has been defined as the "in-depth consideration of events, situations, words, and actions" in order to achieve a deeper understanding of them and how people view themselves through them (Iordanou et al., 2017, p. 38). In essence, it is the "discipline of engaging in reflective practice activities" (Dallos \& Stedmon, 2009 , p. 1). Reflexivity is an ability to take this further towards the "questioning of taken-for-granted assumptions, frames, and mental models" (Yanow \& Tsoukas, 2009, p. 1341). In essence, reflexivity entails deep reflections upon one's habitual perceptions, assumptions, and values (Bolton, 2014, p. xxiii). Perceived in this way, reflexivity is a significant learning and development instrument that plays a central role in our philosophy of coach education.

Both criticality and reflexivity allow the coach to avoid the trap of what Schön (1984, p. 60) called "parochial narrowness of vision." By cultivating these we aim to facilitate reflexive agency in our learners, just like coaches strive to encourage their clients' reflexive agency. This highly constructivist aspect of our pedagogic approach echoes other voices on the significance of 
reflection and reflexivity in management and business education (Reynolds, 1998; Cunliffe, 2002; Gray, 2007; Tompkins \& Ulus, 2015).

\section{Highlighting uncertainty, complexity and paradoxes in the contexts of practice}

Value-neutral instrumentalism and developmentalism see coaching and the world in which it operates in substantially different ways. In contrast to the linear and reductive value-neutral instrumentalist view of the world, developmentalism inherently recognises complexity and therefore aligns to theories such as a Complex Adaptive Systems (CAS) (Stacey, 2003; Cavanagh \& Lane, 2012). The Complex Adaptive Systems model implies that the organisations, clients and their relationships are in a constant state of flux (Stacey, 2003) with many different factors that influence each other, making simple causal relationship between them impossible to identify. According to this view the process of coaching is therefore seen as "a conversational, reflexive narrative inquiry ... as an alternative to restrictive rules and procedures" (Stacey, 2012, p. 95).

In this view, coaching is inevitably challenged by the "blurriness" (Cavanagh \& Lane, 2012) that flux produces and also can itself differ in terms of the form, purpose, context and specific characteristics. Coaching can take the form of a special type of conversation; for example, between a manager and an employee or that of a professional service provided by an executive coach. The purpose here might be to address immediate work challenges, develop skills or to participate in a more developmental learning process. Coaching might equally take place in the workplace with a paying organizational sponsor, or outside the employment context, to work at a more personal level. The characteristics of a coaching session might vary depending on whether the coach's own practice is informed from humanistic or more deterministic principles and other frames of understanding. In light of this, the education and development of coaches requires an approach that does not over-simplify the conditions in which they will work, and highlights the importance of understanding and flexibility, commensurate with the complexity, uncertainty and ambiguity that coaches will experience in their practice.

\section{Practising and arriving at congruence between the self and style of practice}

If coaching operates in client situations that are characterised by uncertainty and complexity with manifold paradoxes, it follows, then, that learning about coaching has to be experiential, reflective and embedded in the 
complexity of real world practice. In keeping with many other postgraduate programmes, our programme's capstone task is a research project or dissertation. This somewhat focuses on declarative and shared knowledge. However, we have argued throughout this paper that coaching is itself a reflexive activity, which attends to the interface between the internal and external worlds of knowledge. So our approach to this is to ask students - (as a capstone task for the first year of the programme) - to articulate their "model of practice," based on the reflection, supervision and theorising around their immediate practice experience.

The framework for this task follows a structure modified from Lane (2006) for the orientation of coaching supervisors (Lane, 2006; Lane \& Corrie, 2015). In essence, it is now based on the structure of Why, What and How of their practice. Our adaptation of the model foregrounds 'philosophy' (why) as an essential and conscious underpinning of the student's model of practice. In this way, the 'purpose' of the intervention - what the practice is intended to achieve - becomes more closely linked to the student's underpinning assumptions and values about life, knowledge and the social world. Finally, the actual design of the practice can be related to and aligned with two other foundational aspects of the coaching model.

For students who may have started their studies, as mentioned previously, expecting a normative pedagogical experience in the 'instrumentalist' mode we have described previously, this exercise can be challenging. Most developing practitioners have not undertaken this sort of reflexive enquiry and ways of thinking philosophically are unfamiliar to most people. Despite that, the exercise can be seen to produce a number of positive outcomes. Students report the development of their coaching model, along with the experimentation and adjustments they make to it in practice, as the foundation for their future development; some report that it enables them to practice with more conviction and more confidence; for most students at the very least it acts as a mechanism to synthesise their practical and theoretical learning. These outcomes reflect, in effect, a process of practice maturation. Students typically experience at the outset an initial struggle to grasp a sense of perspective on a broad body of knowledge (episteme), and uncertain of their own practice they look to 'grab hold' of methods and techniques that they can rely on to work (techne). The integration of this experience into a framework that reflects their own values and beliefs enables a more personal level of enquiry and a practice congruent to the way they see themselves: a reflexive development of phronesis. 


\section{Development of ethical maturity}

We appreciate that the ability to understand others is a crucial aspect of ethical behaviour (Iordanou et al., 2017). Ethical maturity, like reflexive practice, develops gradually, as a conglomeration of experiences, in conjunction with familial, educational, and cultural values, and similarly enables individuals to construct meaning of themselves, their relationships with others, and the world around them (Kegan, 1982). The development of personal maturity goes hand in hand with the growth of ethical maturity (Kohlberg, 1981).

The cultivation of ethical maturity is achieved through the systematic exposure to ethical dilemmas that provides opportunities for conscious reflection on an individual's personal and professional values and beliefs. Continuous exposure to such situations can be challenging, yet amenable to the development of ethical maturity (Iordanou et al., 2015; Iordanou \& Williams, 2017; Iordanou et al., 2017). This is because such settings can encourage debates and discussion on complex ethical issues, promote healthy dissonance, and, ultimately, cultivate tolerance towards the discomfort that ethical dilemmas can generate.

While formal academic credentials do not guarantee the development of ethical maturity, we strongly believe that the process of learning in such settings is enabling for its cultivation. This is precisely because the learning process is built on the co-creation of knowledge within communities of learning, where both instructors and learners can freely exercise critical reasoning. In consequence, such settings can become 'powerhouses of ethical thinking and behaviour', where learners can freely take responsibility for their beliefs and values, while sharing their views in a joint effort to develop ethical consciousness and enhance their ethical maturity (Iordanou et al., 2017, p. 151).

\section{Challenges our philosophy presents}

It is probably clear from the description of the principles of our programmes that it is extremely rewarding to work with developing coaches in a way that is congruent to what we believe in and value. However, as every choice has consequences, it is both important and useful to describe the challenges that we face, and the questions that we struggle with, within the constraints of an academic institution. Amongst the most prominent issues are:

- Meeting formal assessment requirements

- Potentially losing students who are not ready for such a process 
- Forming expectations of students and ascertaining what progress looks like

\section{Meeting formal assessment requirements}

By formulating our programme in constructivist and pragmatic terms we create something of a challenge in assessment of students' progress. On the one hand, some of the qualities that we most value - in particular, development of self and reflexivity - are more problematic to assess than are, for example, the acquisition or even application of knowledge. Indeed, there is some educational debate about the feasibility or appropriateness of assessing such qualities. Bourner (2003) points out the conflict between objective measurement and subjective experience, while Brockbank \& McGill (2007, p. 195) helpfully differentiate the tendency for learning outcomes to point towards the assessment of product, while the interest in reflective learning and reflexivity may be one of process. For all these authors, along with Moon (2013), the issues above are not insurmountable with some thought. Our own approach starts with dialogue on the meaning of these concepts and a constructive exploration of what it means to learn more deeply, and to reflect on the self and one's own perspective. Assessment focuses on how that understanding of the process of reflexivity is applied to real-life practice issues as they arise.

A second issue of assessment that presents itself under this general view of professional development lies in the role of skills and skills assessment. To restate the underpinning outlook on professional education, it is that through reflective learning, criticality and a mastery of a sufficient body of knowledge, students will be equipped to develop a practice that is robust, effective and ethical. Given that this inherently implies a 'journey' metaphor of learning (see Garvey, 2017), allied to the somewhat problematic nature of competency frameworks that we have already described, it seems nonsensical to assess students skills so far as they have developed at a particular time. The mismatch this creates with professional bodies and accreditation processes has already been explored in this paper. Nonetheless, this seems to be a secondary problem to the alternative: to provide a learning experience and assessment regime that is incongruent with the philosophy underlying coaching practice itself.

\section{Potentially losing students who are not ready for such a process}

This approach to coach training and education necessitates embracing uncertainty, complexity, and paradox that the coaching practice can entail. This is a challenging request to make of learners, who might expect a more 
normative, teacher-centred approach. Yet, embracing and expressing uncertainty, complexity, and paradox as a way of facilitating subjectivity, sensitivity, interaction, and responsibility (Sutherland, 2013) is a testing task that can disaffect and even distance learners from such training programmes that employ a constructivist approach to learning. In addition to many other aspects of learning we attach great meaning to the process of critical reflexivity as a process entering what Schön $(1987$, p. 297) called the "hall of mirrors," in order to create reflective practitioners who examine and re-examine their practice. For this reason, it might be worth accepting that this learning approach might, indeed, not be for everyone.

One of the options is to accept this situation, and simply communicate to potential students our pedagogical and practice principles, such that they are able to make their choices before accepting the offer. This would be unsatisfactory for us for two reasons. Firstly, because it contradicts our own philosophy of developmentalism that implies that everyone has the right to be where they are in their developmental journey and learn in tune with their unique self. Secondly, because providing sufficient information is not as easy as it sounds (see our next challenge). At the moment, we address the problem of readiness for this type of learning by providing students who find it difficult with opportunities to explore themselves and by giving feedback that is scaffolding by its nature, not in relation to particular standards, but in relation to the next steps that seem available for them. The remaining problem is that such scaffolding is highly subjective and may also be seen as vague and insufficient. We are currently able to counter institutional pressures (Mohrman, Ma \& Baker, 2008) to relax these elements of challenge to those who may struggle with our philosophical approach, due to the strong external and internal support, via formal validations, and wider recognition of the learning experienced and reported by our alumni.

\section{Forming expectations of students and ascertaining what progress looks like}

The problem of giving information to form expectations of our approach and associated learning process is that this experience is often unsubscribed, highly individualised and contextualised, bordering, at times on the ethereal. Articulating it is frustrating for those who are in a position to describe this process, but aware of how futile their attempt might be. Even guiding learners through this domain of self-discovery as they develop their practice is not a pedestrian endeavour, but explaining the miscellany of experiences learners will encounter is of a higher order. Here the challenges identified by others in 
training, educating and developing coaches (Western, 2012; Gray, 2010; Lane, 2017; Cox, 2013; Bachkirova, 2011; Worth, 2012) are reinforced.

On the receiving end of the information about learning trajectory, it typically creates a sense of precariousness amongst the more timid and a real ache for knowledge and experience for those conditioned to clear protocols and answers. It may ring hollow initially, and every cohort, despite signalling in communication, identifies those who were not quite prepared for the level of critical engagement, interaction and personal challenge involved in the programme.

There are also significant challenges in providing feedback that is meaningful at each particular stage of the student struggle with the process. It requires charting progress towards some benchmarks, which must be mapped in an academic frame in our world. To provide such tailored guidance and flexibility we continue to engage in a dialogue between peers, faculty, clients and supervisors to share insights and accumulate experience. However, the paradox of meeting expectations remains. It seems impossible to make the route to progress explicit and consensual. If the type of education that we offer changes the perspective and potentially the mindset of the student, but some students do not know what to expect and how to evaluate if their expectations are met, we have to rely as educators on our own interpretation of their feedback.

\section{Conclusions}

It seems that no approaches to coach education are without controversies. In this paper, we have shared our concerns and described the choices that we made based on the underpinning philosophical principles of pragmatism and constructivism. We explored the questions that remain our concerns in relation to both the congruence with these principles and practicalities of making them work in the process of educating coaches. In spite of these concerns we believe that developmentalism is a more powerful and appropriate stance for coach education in comparison to the alternative value-neutral instrumentalism. First of all, it aligns better with the fundamental attributes of professionalism in this field - a value that all stakeholders of coaching share. Secondly, it more closely defines what is implicit in many coaches' practice and thus provides a clearer framework than more general claims to align to, e.g. 'humanism.'

Finally, it is our wish that the themes raised here are seen as an invitation to share all views and to challenge our choices. These topics are relevant not 
only to educators - we hope to stimulate the voices of students, past and current. In relation to professional bodies, the messages of this paper add to those already expressed challenges to accreditation systems. We urge professional bodies to engage with the problematizing of such systems in relation to the development of professionalism.

\section{References}

Alvesson, M. (2001). Knowledge work: Ambiguity, image and identity, Human Relations, 54(7), 863-886.

Bachkirova, T. (2011). Developmental Coaching: Working with the Self. Maidenhead: Open University Press.

Bachkirova, T. (2017). 'Developing a Knowledge Base of Coaching: Questions to Explore' in T. Bachkirova, G. Spence, and D. Drake (eds), The SAGE Handbook of Coaching (pp. 23-41). London: SAGE Publications Ltd.

Bachkirova, T., Cox, E., and Clutterbuck, D. (2014). 'Introduction', in E. Cox, T. Bachkirova, and D. Clutterbuck (eds), The Complete Handbook of Coaching, $2^{\text {nd }}$ edn. (pp. 1-18). London: SAGE Publications Ltd.

Bachkirova, T. and Lawton Smith, C. (2015) 'From competencies to capabilities in the assessment and accreditation of coaches', International Journal of Evidence Based Coaching \& Mentoring, 13(2), $123-140$.

Bachkirova, T. (2016) The Self of the Coach: Conceptualization, Issues, and Opportunities for Practitioner Development, Consulting Psychology Journal: Practice and Research, 68(2), 143-156.

Bluckert, P. (2004). The state of play in corporate coaching: Current and future trends. Industrial and Commercial Training, 32, 53-56.

Bolton, G. (2014). Reflective Practice: Writing and Professional Development. $4^{\text {th }}$ edn. London: SAGE Publications Ltd.

Bond, T. (2015), Standards and Ethics for Counselling in Action, $4^{\text {th }}$ edn. London: SAGE Publications Ltd.

Bono, J., Purvanova, R., Towler, A. \& Peterson, D. (2009). A Survey of Executive Coaching Practices. Personnel Psychology, 62(2), 361-404.

Bourner, T. (2003) 'Assessing reflective learning', Education + Training, 45(5), 267-272.

Boyatzis, R. (2006). 'An overview of intentional change from a complexity perspective'. Journal of Management Development, 25, 607-623.

Brockbank, A. and McGill, I. (2007) Facilitating Reflective Learning In Higher Education. McGraw-Hill Education (UK).

Carroll, M. \& Shaw, E. (2013). Ethical Maturity in the Helping Professions: Making Difficult Life and Work Decisions. London: Jessica Kingsley. 
Cavanagh, M. \& Lane, D. (2012). Coaching Psychology Coming of Age: The challenges we face in the messy world of complexity? International Coaching Psychology Review, 7(1), 75-90.

Cox, E. (2013). Coaching Understood: A Pragmatic Inquiry into the Coaching Process. London: SAGE Publishing.

Cunliffe, A. L. (2002). Reflexive dialogical practice in management learning. Management Learning, 33, 35-61.

Dallos, R., \& Stedmon, J. (2009). Flying over the swampy lowlands: reflective and reflexive practice. In J. Stedmon, \&. R. Dallos, R. (eds) Reflective Practice in Psychotherapy and Counselling (pp. 1-22). Maidenhead: Open University Press.

Drake, D. B. (2008). 'Finding our way home: Coaching's search for identity in a new era'. Coaching: An international journal of theory, research and practice, 1(1), 16-27.

Drake, D. B. (2015). Narrative Coaching: Bringing Our New Stories to Life. Petaluma, CA: CNC Press.

de Haan, E. et al. (2013) 'Executive coaching outcome research: The contribution of common factors such as relationship, personality match, and self-efficacy.', Consulting Psychology Journal: Practice and Research, 65(1), 40-57.

Dewey, J. (1916). Democracy and Education: an introduction to the philosophy of education. London: Macmillan.

Eisner, E. W. (2002) 'From episteme to phronesis to artistry in the study and improvement of teaching', Teaching and Teacher Education, 18(4), 375-385.

Fillery-Travis, A. and Collins, R (2017), 'Discipline, profession and industry: How our choices shape our future', in T. Bachkirova, G. Spence, and D. Drake (eds), The SAGE Handbook of Coaching (pp. 729-744). London: SAGE Publications Ltd.

Garvey, B. (2017) Issues of assessment and accreditation of coaches, in Bachkirova, T., Spence, G., and Drake, D. (eds) The SAGE handbook of coaching, (pp. 680-695), London: SAGE Publications Ltd.

Garvey, B. (2011). A Very Short, Fairly Interesting and Reasonably Cheap Book About Coaching and Mentoring. London: SAGE Publishing.

Garvey, B., Stokes, P. and Megginson, D. (2014) Coaching and mentoring: theory and practice. 2nd edn. London: SAGE Publications Ltd.

Grant, A. (2013). The efficacy of coaching. In J. Passmore, D. Peterson and T. Freire (eds.), The Wiley-Blackwell Handbook of the Psychology of Coaching and Mentoring (pp. 15-39). Chichester: Wiley-Blackwell. 
Gray, D. E. (2007). Facilitating management learning: Developing critical reflection through reflective tools. Management Learning, 38, 495-517.

Gray, D. E. (2011). Journeys towards the professionalisation of coaching: Dilemmas, dialogues and decisions along the global pathway. Coaching: An International Journal of Theory, Research and Practice, 4(1), 4-19.

Gray, D. E., Garvey, B., \& Lane, D. A. (2016). A Critical Introduction to Coaching and Mentoring: Debates, Dialogues and Discourses. London: SAGE Publications Ltd.

Greiner, L., \& Ennsfellner, I. (2010). 'Management consultants as professionals, or are they?', Organizational Dynamics, 39(1), 72-83.

Health and Care Professionals Council (2014). Professionalism in health care professionals. London: Health and Care Professionals Council, http://www.hpc-

uk.org/assets/documents/10003771Professionalisminhealthcareprofessio nals.pdf, accessed 23.09.17.

Iordanou, I., Hawley, R., \& Iordanou C. (2017). Values and Ethics in Coaching. London: SAGE Publishing.

Iordanou, I., \& Williams, P. (2017). Developing Ethical Capabilities for Coaches. In T. Bachkirova, G. Spence, \& D. B. Drake (eds), The SAGE Handbook of Coaching. (pp. 696-712). London: SAGE Publications Ltd.

Iordanou, I., Leach, A., \& Barnes, V. (2015). Coaching in Higher Education, in C. van Nieuwerburgh (ed), Coaching in Professional Contexts (pp. 14558). London: SAGE Publications Ltd.

Ives, I., \& Cox. E. (2014). Relationship Coaching: The Theory and Practice of Coaching with Singles, Couples, and Parents. London: Routledge.

Jackson, P. (2004) 'Understanding the experience of experience: A practical model of reflective practice for coaching', International Journal of Evidence-based Coaching and Mentoring, 2(1), 57-67.

Jones-Devitt, S., and Smith, L. (2007) Critical Thinking in Health and Social Care. London: SAGE Publications Ltd.

Kegan, R. (1982). The Evolving Self: Problems and Process in Human Development. Cambridge, MA: Harvard University Press.

Kim, H. S. (1999) Critical reflective inquiry for knowledge development in nursing practice, Journal of Advanced Nursing, 29(5), 1205-1212.

Kohlberg, L. (1981). Essays on Moral Development (Vol. 1): The Philosophy of Moral Development. San Francisco, CA: Harper and Row.

Krapu, T. (2016). Coaching from the Philosophy of Science perspective. Philosophy of Coaching: An International Journal, 1(1), 8-20. 
Lane, D.A. (2017). Trends in Development of Coaches (Education and Training): Is it Valid, Is it Rigorous and Is it Relevant?, in T. Bachkirova, G. Spence, \& D. B. Drake (eds), The SAGE Handbook of Coaching (pp. 647-661). London: SAGE Publications Ltd.

Lane, D. (2006) The Emergence of Supervision Models. Presentation at the Annual Conference of the Special Group in Coaching Psychology of the $B P S$, (unpublished).

Lane, D. and Corrie, S. (2015). Cognitive-behavioural formulation and the scientist-practitioner: Working with an adolescent boy. In Bruch, M. (ed.) Beyond diagnosis: Case formulation in Cognitive Behavioural Therapy. 2nd edn. Chichester: Wiley-Blackwell.

Lane, D., Stelter, R. and Stout-Rostron, S. (2014). The Future of Coaching as a Profession. In E. Cox, T. Bachkirova and D. Clutterbuck (Eds.) The Complete Handbook of Coaching (pp. 377-390), London: Sage.

Mezirow, J. (1990). Fostering Critical Reflection in Adulthood. San Francisco: Jossey-Bass.

Mohrman, K., Ma, W., \& Baker, D. (2008). The research university in transition: The emerging global model. Higher education policy, 21(1), 5-27.

Moon, J. A. (2013) A Handbook of Reflective and Experiential Learning: Theory and Practice. London: Routledge.

Nelson, E., and Hogan, R. (2009). Coaching on the dark side. International Coaching Psychology Review, 4, 9-22.

Palmer, S. (2008). Multimodal coaching and its application to workplace, life and health coaching. The Coaching Psychologist, 4, 21-29.

Reynolds, M. (1998). Reflection and critical reflection in management learning. Management Learning, 29, 183-200.

Rogers, J. (2012). Coaching Skills: A Handbook ( $3^{\text {rd }}$ ed). Maidenhead: Open University Press.

Schön, D.A. (1987). Educating the Reflective Practitioner. San Francisco, CA: Jossey-Bass.

Schön, D.A. (1984). The Reflective Practitioner: How Professionals Think in Action. New York: Basic Books.

Shoukry, H. (2017). Coaching for Social Change. In T. Bachkirova, G. Spence and D. Drake (eds.) The SAGE Handbook of Coaching, (pp. 176-194), London: SAGE Publications Ltd.

Stacey, R. D. (2003). Strategic management and organisational dynamics: The challenge of complexity. Harlow: Prentice-Hall. 
Stacey, R. D. (2012). Comment on debate article: Coaching Psychology Coming of Age: The challenges we face in the messy world of complexity. International Coaching Psychology Review, 7(1): 91-95.

Stein, I. F., Page, L. J., \& Maltbia, T. E. (2014). Coaching education: Coming of age. Journal of Psychological Issues in Organizational Culture, 5(2), 7-15.

Stelter, R. (2014). Third generation coaching: Reconstructing dialogues through collaborative practice and a focus on values. International Coaching Psychology Review, 9(1), 51-66.

The Quality Assurance Agency for Higher Education (QAA) (no date). Available at: http://www.qaa.ac.uk:80/publications/information-andguidance/publication?PubID=2843 (Accessed: 18 July 2017).

Tomkins, L., \& Ulus, E. (2015). Is narcissism undermining critical reflection in our business schools? Academy of Management Learning and Education 14, 595-606.

Van Nieuwerburgh, C. (2017). An Introduction to Coaching Skills: A practical guide. $2^{\text {nd }}$ edn. London: SAGE Publishing.

Visscher, K. (2006). Capturing the competence of management consulting work. Journal of Workplace Learning, 18(4), 248-260.

Wampold, B. E. (2001) The great psychotherapy debate: Models, methods and findings. Marwah, NJ: Lawrence Erlbaum.

Western, S. (2012). Coaching and Mentoring: A Critical Text. London: SAGE Publications Ltd.

White, S., Fook, J. and Gardner, F. (2006). Critical reflection in health and social care. Maidenhead: Open University Press.

Williams, P., Lindberg W. H, \& Anderson, S. K. (2006). Coaching to come. In Williams, P. \& Anderson, K. S. (2006) (Eds.), Law and Ethics in Coaching: How to Solve - and Avoid - Difficult Problems in Your Practice (pp. 245-56). Hoboken, NJ: John Wiley \& Sons.

Worth, S., (2012). An Exploration of coaching women towards authenticity in the workplace: A Heuristic study with women in academia. Unpublished Doctorate in Coaching \& Mentoring, Oxford Brookes University.

Wright, J. (2012). Reflective Writing in Counselling and Psychotherapy. London: SAGE Publications Ltd.

Yanow, D., \& Tsoukas, H. (2009). What is reflection-in-action? A phenomenological account. Journal of Management Studies, 46, 133964.

\section{Author Contact}

tbachkirova@brookes.ac.uk 